\title{
Ex-vivo Immune-stimulating Activity of Scutellaria baicalensis and Its Major Flavonoids on Human Immune Cells Rudolf Vrabec $\oplus^{1}$, Doris Vokurková $\odot^{2}$, Lenka Tůmová $\oplus^{1}$ and José Cheel $\oplus^{* 3}$
}

\author{
${ }^{I}$ Department of Pharmacognosy, Faculty of Pharmacy, Charles University, Akademika Heyrovského \\ 1203/8, 50005 Hradec Králové, the Czech Republic \\ ${ }^{2}$ Institute of Clinical Immunology and Allergology, Faculty of Medicine and University Hospital, \\ Charles University, Sokolská 581, 50005 Hradec Králové, the Czech Republic \\ ${ }^{3}$ Laboratory of Algal Biotechnology-Centre ALGATECH, Institute of Microbiology of the \\ Czech Academy of Sciences, Opatovický mlýn, Novohradská 237, 37981 Třeboñ, the Czech \\ Republic
}

(Received February 17, 2021; Revised June 03, 2021; Accepted June 04, 2021)

\begin{abstract}
This study investigates the activation of human immune cells (T, B, and NK cells, and granulocytes) by the ethanolic and aqueous extracts of Scutellaria baicalensis root (SBR) and to identify the compounds responsible for such an effect. The cell activation was determined by expression of the cell surface glycoprotein CD69 (cluster of differentiation 69), as measured by flow cytometry. The content of the main flavonoids in SBR extracts was estimated by high performance liquid chromatography with a diode array detector. NK cells were substantially activated by the SBR ethanolic extract $(25-200 \mu \mathrm{g} / \mathrm{mL})$, whereas B cells were activated on a lower scale. NK cells were slightly activated by the SBR aqueous extract (100-200 $\mu \mathrm{g} / \mathrm{mL})$. Wogonoside and baicalin, two major flavonoids present in the SBR extracts, exhibited the highest activation effect on NK cells. The content of baicalin, wogonoside, and baicalein accounted for 201.2, 47.7, and $3.4 \mathrm{mg} / \mathrm{g}$ in the ethanolic extract; and for $150.4,33.6$, and $4.6 \mathrm{mg} / \mathrm{g}$ in the aqueous extract, respectively. This study shows the immune-stimulating properties of SBR extracts and identifies their active compounds. This data may support the potential utilization of SBR for strengthening the human immune system against bacterial and viral infections.
\end{abstract}

Keywords: Scutellaria baicalensis; immune-stimulation; CD69; flavonoids; baicalin; baicalein; wogonoside. (C) 2021 ACG Publications. All rights reserved.

\section{Plant Source}

The roots of Scutellaria baicalensis Georgi (Lamiaceae) were collected in the Experimental Garden of the Faculty of Horticulture, Mendel University in Brno (the Czech Republic). The voucher

\footnotetext{
*Corresponding author: E- Mail: jcheel@email.cz ( J. Cheel); Phone +420-384340465 . 
specimen (No. AL-748) was verified and deposited by Prof. Lubomír Opletal in the herbarium of the Faculty of Pharmacy in Hradec Králové (the Czech Republic).

\section{Previous Studies}

Scutellaria baicalensis Georgi (Baikal skullcap) is a perennial herb native to east Asia. Its root is commonly used in traditional Chinese Medicine [1,2]. More than forty flavonoids have been reported as the main active secondary metabolites in Scutellaria baicalensis roots (SBR) [2]. They are predominantly represented by baicalin (1), accounting up to $20 \%$ in the root, and its aglycon baicalein (2) (Figure 1) [3]. Other flavonoids present in SBR include wogonoside (3) (Figure 1) and its aglycon wogonin, norwogonin, scutellarin and its aglycon scutellarein, oroxylin A, and skullcapflavone I and II. SBR also contains small amounts of essential oils, lignan glycosides, sterols, and amino acids [3,4].<smiles>O=C(O)[C@H]1CC(Oc2cc3oc(-c4ccccc4)cc(=O)c3c(O)c2O)[C@H](O)[C@@H](O)[C@H]1O</smiles><smiles>O=c1cc(-c2ccccc2)oc2cc(O)c(O)c(O)c12</smiles><smiles>CCc1c(OC2CC(C(=O)O)[C@@H](O)[C@H](O)[C@H]2O)c(O)c(O)c2c(=O)cc(-c3ccccc3)oc12</smiles>

Figure 1. Chemical structures of baicalin (1), baicalein (2), and wogonoside (3)

Besides exhibiting a wide range of biological activities [1], SBR has been suggested as a promising immune-modulating agent [5-13]. Indeed, SBR extract was shown to modulate mice immunity through both the regulation of type 1 and type 2 helper $\mathrm{T}$ cells, and the inhibition of the production of interferon-gamma (IFN- $\gamma$ ), nitric oxide (NO), interleukin 12 (IL-12), and tumor necrosis factor alpha (TNF- $\alpha$ ) [5]. This extract also normalized the count of T-lymphocytes, immunoglobulin A, and granulocytes in patients undergoing antineoplastic chemotherapy [6,7]. Furthermore, a SBR extract enriched in baicalein and wogonin has been reported to upregulated innate antiviral immunity by modulating cytokine production and stimulating human leukocyte resistance [8]. In another study [9], a SBR extract standardized to baicalin was found to induce apoptosis in leukocytes of children diagnosed with acute lymphocytic leukemia. Baicalin is the most abundant secondary metabolite present in SBR and several studies have been mainly focused on this compound to ascertain its involvement in the immune-modulating activities of SBR. In fact, previous investigations have demonstrated that baicalin stimulates the production of INF- $\gamma$ in T-lymphocytes and natural killer (NK) cells, as revealed by a study on mice in vivo and on human blood leukocytes in vitro [10]. It has also been reported that baicalin stimulates the proliferation of $\mathrm{T}$ - and $\mathrm{B}$-cells [11], and may promote regulatory $\mathrm{T}$ cells differentiation and upregulate the inhibitory function of regulatory and effector $\mathrm{T}$ cells [12]. However, not only flavonoids are responsible for the claimed immune-modulating effect of SBR. For instance, a water-soluble polysaccharide glucan (SbRP-1) from SBR showed an immunestimulating effect on the azathioprine model of immunosuppression [13]. Therefore, it is conceivable that the effect of SBR and its components on immunity may differ depending on the method or model used to study this property. SBR-based phytopreparations are mostly available as ethanolic tinctures or herbal teas, which have not been extensively evaluated for their immune-stimulating effects. In addition, no study has determined the contribution of SBR flavonoids to this bioactivity.

\section{Present Study}

In the present study, the capacity of two SBR extracts and their main flavonoids to activate human immune cells was investigated ex vivo by measuring the expression of CD69 (cluster of differentiation 69) on the surface of human immune cells. The content of the main flavonoids in the SBR extracts was determined by high performance liquid chromatography with a diode array detector (HPLC-DAD). It is known that upon activation with a variety of stimuli (like IL-2, TNF- $\alpha$, cell 


\section{Immune-stimulating activity of Scutellaria baicalensis}

antigens, or viral infections), human immune cells (T, B, and NK cells, monocytes, neutrophils, and eosinophils) express CD69 transmembrane glycoprotein on their surface, which functions as a signaltransmitting receptor and helps co-stimulate further activation and proliferation. CD69 is one of the earliest activation markers [14,15]. Anti-human CD69 antibodies can be fluorescently marked; therefore, it is possible to measure their fluorescence intensity by flow cytometry. In this way, the activation of immune cells was possible to be estimated (in Supporting Information). This method has been used to evaluate the immune-stimulating properties of medicinal herbs [16,17]. As seen in Figure 2C, the SBR ethanolic extract led to a substantial increase in the number of activated NK cells, but a slight increase in the number of activated total lymphocytes (Figure 3C) after $24 \mathrm{~h}$ of treatment. The SBR aqueous extract afforded a slight increase in the number of activated NK cells and total lymphocytes (Figures 2D, 3D). The CD69 expression on activated NK cells and total lymphocytes in response to $\mathrm{SBR}$ treatment was shown as a shift to the right in the representative histograms (Figures 2C-D, 3C-D). The B and T cells (figures not shown) exhibited only a negligible increase in their number in response to ethanolic SBR treatment. As shown in Tables 1 and 2, the stimulation index of ethanolic and aqueous SBR extracts $(25-200 \mu \mathrm{g} / \mathrm{mL}$ ) on the tested immune cells (as described in Supporting Information) confirmed these observations. The SBR ethanolic extract exerted a better stimulation index on the immune cells than the SBR aqueous extract (Tables 1,2). However, the two studied SBR extracts showed almost no effect on granulocytes (Tables 1,2). The slight stimulation index on B cells in response to SBR extracts treatment was similar to that observed over total lymphocytes. As shown in Table 3, wogonoside, followed by baicalin were the most active flavonoids over the tested immune cells. Except T cells, all tested immune cells were activated by these two compounds. Baicalin (1) is the $\beta$-D-glucuronic acid-conjugated form of baicalein (2); in other terms, baicalein is the aglycone part of the molecule. Therefore, it is conceivable that glucuronic acid may play a fundamental role in the activation effect showed by baicalin. Surprisingly, baicalin (1) and wogonoside (3) (another flavonoid glycoside conjugated with $\beta$-D-glucuronic acid) were the most active compounds in this study, thus suggesting the vital role of glucuronic acid in the immunestimulation effect exerted by these two compounds. This led us to hypothesize that unlike the aglycones, the increased hydrophilicity of $\mathbf{1}$ and $\mathbf{3}$ may facilitate these compounds to solubilize better in the assay aqueous media, thereby favoring their access to cells for exerting their effect.

The HPLC analysis of the SBR extracts (Figure S1) confirmed the presence of the flavonoids $\mathbf{1}$, 2, and 3. The SBR ethanolic extract contained 201.2 and $47.7 \mathrm{mg} / \mathrm{g}$ of $\mathbf{1}$ and $\mathbf{3}$; respectively, while the SBR aqueous extract was found to contain 150.4 and $33.6 \mathrm{mg} / \mathrm{g}$ of $\mathbf{1}$ and $\mathbf{3}$, respectively (Table S1). Baicalein was the minor flavonoid in the two tested extracts (Table S1). Baicalin has been earlier reported as the major flavonoid in the SBR, while its aglycon baicalein is present at lower concentrations [3]. A previous study has reported wogonoside as the second most abundant flavonoid in SBR [3]. In the present study, the detected amounts of flavonoids in SBR extracts were consistent with those reported in the literature [3,18]. Other flavonoids in SBR represent less than $1.0 \%(\mathrm{w} / \mathrm{w})$ [3]. In the current investigation, the immune-stimulating activity of the SBR ethanolic extract might be attributed to baicalin and wogonoside.

Table 1. Stimulation index of the ethanolic extract of Scutellaria baicalensis on immune cells

\begin{tabular}{|c|c|c|c|c|c|}
\hline \multirow{3}{*}{ Cell type } & \multicolumn{5}{|c|}{ SI (stimulation index) } \\
\hline & \multicolumn{4}{|c|}{ concentration $(\mu \mathrm{g} / \mathrm{mL})$} & \multirow[b]{2}{*}{$\mathbf{P W M}^{\mathbf{a}}$} \\
\hline & 25 & 50 & 100 & 200 & \\
\hline NK cells & $6.7 \pm 3.5$ & $17.9 \pm 10.4$ & $15.5 \pm 7.0$ & $21.0 \pm 9.4$ & $39.7 \pm 6.1$ \\
\hline Total lymphocytes & $2.6 \pm 0.6$ & $2.2 \pm 1.2$ & $5.4 \pm 1.4$ & $7.2 \pm 2.3$ & $26.0 \pm 9.3$ \\
\hline $\mathrm{T}$ cells & $1.7 \pm 0.1$ & $1.2 \pm 0.5$ & $2.4 \pm 0.2$ & $2.8 \pm 0.6$ & $17.5 \pm 6.5$ \\
\hline B cells & $2.6 \pm 0.6$ & $2.1 \pm 1.2$ & $5.2 \pm 1.4$ & $7.0 \pm 2.3$ & $25.5 \pm 9.5$ \\
\hline Granulocytes & $1.5 \pm 0.3$ & $0.8 \pm 0.0$ & $0.6 \pm 0.1$ & $0.5 \pm 0.1$ & $7.9 \pm 0.3$ \\
\hline
\end{tabular}

a PWM (positive control): pokeweed mitogen at a concentration of $10 \mu \mathrm{g} / \mathrm{mL}$ 
Vrabec et al., Rec. Nat. Prod. (2022) 16:2 188-193

Table 2. Stimulation index of the aqueous extract of Scutellaria baicalensis on immune cells.

\section{SI (stimulation index)}

\begin{tabular}{cccccc}
\cline { 2 - 5 } Cell type & \multicolumn{5}{c}{ concentration $(\boldsymbol{\mu g} / \mathbf{m L})$} \\
\cline { 2 - 6 } & $\mathbf{2 5}$ & $\mathbf{5 0}$ & $\mathbf{1 0 0}$ & $\mathbf{2 0 0}$ & PWM $^{\mathbf{a}}$ \\
\hline NK cells & $1.2 \pm 0.1$ & $2.7 \pm 1.3$ & $4.5 \pm 2.0$ & $6.9 \pm 2.5$ & $39.7 \pm 6.1$ \\
Total lymphocytes & $0.9 \pm 0.1$ & $1.5 \pm 0.2$ & $2.0 \pm 0.3$ & $2.7 \pm 0.3$ & $26.0 \pm 9.3$ \\
T cells & $0.8 \pm 0.1$ & $1.2 \pm 0.0$ & $1.5 \pm 0.1$ & $1.5 \pm 0.0$ & $17.5 \pm 6.5$ \\
B cells & $0.9 \pm 0.1$ & $1.5 \pm 0.2$ & $2.0 \pm 0.3$ & $2.6 \pm 0.3$ & $25.5 \pm 9.5$ \\
Granulocytes & $0.5 \pm 0.1$ & $0.8 \pm 0.1$ & $1.2 \pm 0.1$ & $2.4 \pm 0.0$ & $7.9 \pm 0.3$
\end{tabular}

${ }^{a}$ PWM (positive control): pokeweed mitogen at a concentration of $10 \mu \mathrm{g} / \mathrm{mL}$

Table 3. Stimulation index of baicalin (1), wogonoside (3), and baicalein (2) on immune cells. The compounds were tested at $100 \mu \mathrm{g} / \mathrm{mL}$.

\begin{tabular}{ccccc}
\hline \multirow{2}{*}{ Cell type } & \multicolumn{4}{c}{ SI (stimulation index) } \\
\cline { 2 - 5 } & Baicalin (1) & Baicalein (2) & Wogonoside (3) & PWM $^{\mathbf{a}}$ \\
\hline NK cells & $9.2 \pm 0.8$ & $1.6 \pm 0.6$ & $25.2 \pm 0.2$ & $39.7 \pm 6.1$ \\
Total lymphocytes & $2.7 \pm 0.1$ & $1.0 \pm 0.3$ & $3.4 \pm 0.9$ & $26.0 \pm 9.3$ \\
T cells & $2.0 \pm 0.2$ & $0.8 \pm 0.2$ & $2.1 \pm 0.8$ & $17.5 \pm 6.5$ \\
B cells & $3.0 \pm 0.0$ & $1.1 \pm 0.4$ & $4.1 \pm 1.6$ & $25.5 \pm 9.5$ \\
Granulocytes & $2.9 \pm 0.6$ & $2.0 \pm 1.1$ & $7.4 \pm 1.9$ & $7.9 \pm 0.3$ \\
\hline
\end{tabular}

${ }^{\mathrm{a}} \mathrm{PWM}$ (positive control): pokeweed mitogen at a concentration of $10 \mu \mathrm{g} / \mathrm{mL}$

$\mathbf{A}$
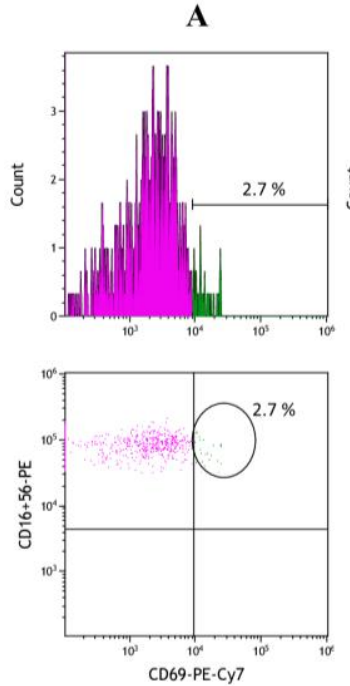

B
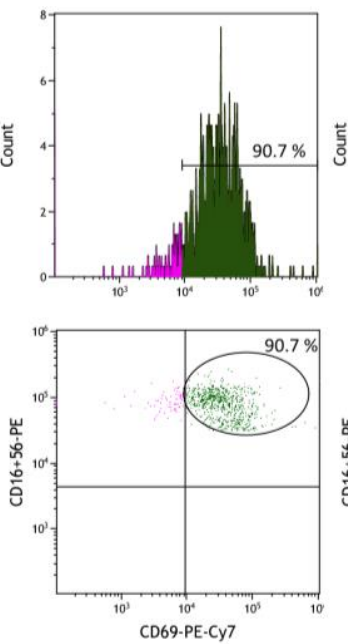

C
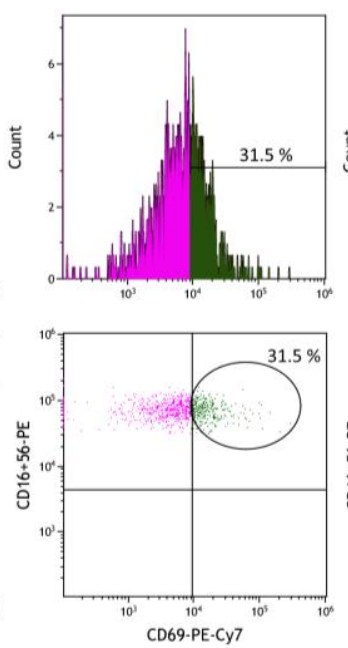

D
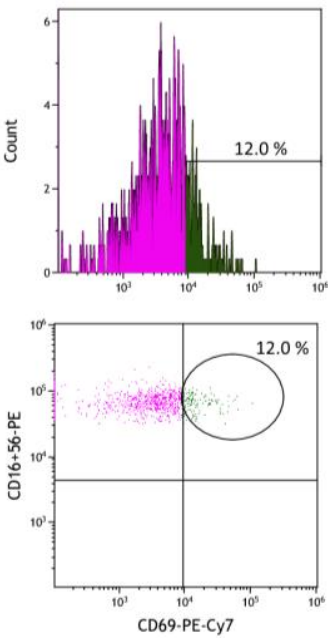

Figure 2. Representative histograms (upper side) and dot plots (lower side) showing the activation of NK cells in response to treatment with SBR extracts. A: Negative control, B: positive control, C: SBR ethanolic extract at $200 \mu \mathrm{g} / \mathrm{mL}$, and D: SBR aqueous extract at $200 \mu \mathrm{g} / \mathrm{mL}$. The pink color on the left represents the number of non-activated NK cells (no expression of antigen CD69 on their surface) and the green color on the right represents the number of activated NK cells 

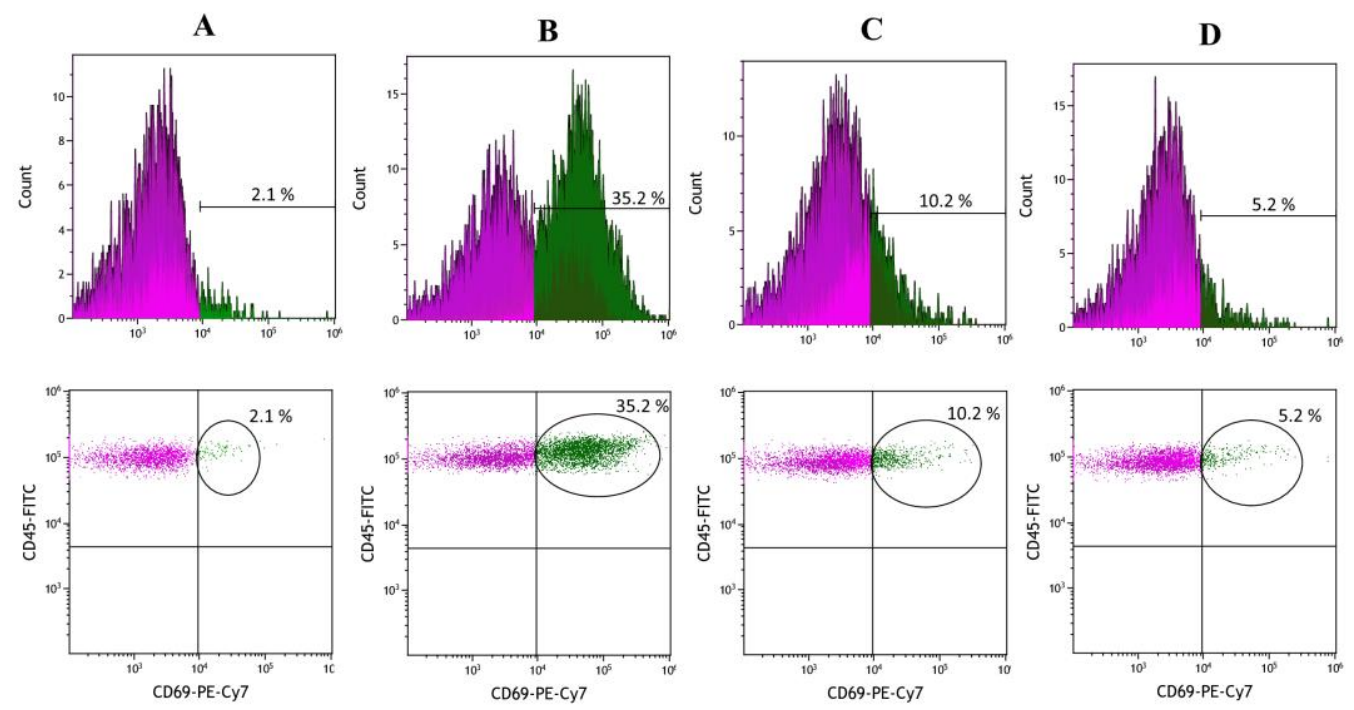

Figure 3. Representative histograms (upper side) and dot plots (lower side) showing the activation of total lymphocytes in response to treatment with SBR extracts. A: Negative control, B: positive control, C: SBR ethanolic extract at $200 \mu \mathrm{g} / \mathrm{mL}$, and D: SBR aqueous extract at $200 \mu \mathrm{g} / \mathrm{mL}$. The pink color on the left represents the number of non-activated lymphocytes (no expression of antigen CD69 on their surface) and the green color on the right represents the number of activated total lymphocytes.

In conclusion, SBR stimulated substantially human NK cells, and a similar effect was exerted by $\mathbf{1}$ and $\mathbf{3}$, the major flavonoids in the tested extracts. Accordingly, it is conceivable that these compounds may be the active principle responsible for the observed effect. Unlike the SBR aqueous extract, the ethanolic extract had a better ability to stimulate the expression of CD69, which correlated with its higher content of $\mathbf{1}$ and $\mathbf{3}$.

\section{Acknowledgments}

This work was funded by the project SVV 260 550. We thank Prof. Pavel Valíček and Prof. Jarmila Neugebauerová for providing botanical material, and Prof. Lubomír Opletal for the deposition of voucher specimen. J.C. thanks the NPU program, MŠMT of the Czech Republic (ID: LO1416).

\section{Supporting Information}

Supporting Information accompanies this paper on http://www.acgpubs.org/journal/recordsof-natural-products

\section{ORCID}

Rudolf Vrabec: 0000-0001-9390-9202

Doris Vokurková: 0000-0001-6979-2825

Lenka Tůmová: 0000-0003-3285-5292

José Cheel: 0000-0001-5789-9297 


\section{References}

[1] T. Weici and G. Eisenbrand (2011). Handbook of Chinese Medicinal Plants: Chemistry, Pharmacology, Toxicology. Volume 2. Wiley-VCH, Weinheim.

[2] T.T. Zhao, H.L. Tang, L. Xie, Y. Zheng, Z.B. Ma, Q. Sun and X.F. Li (2019). Scutellaria baicalensis Georgi. (Lamiaceae): a review of its traditional uses, botany, phytochemistry, pharmacology and toxicology, J. Pharm. Pharmacol. 71, 1353-1369.

[3] J.A. Duke (1992). Handbook of phytochemical constituents of GRAS herbs and other economic plants. FL. CRC Press, Boca Raton.

[4] G.Z. Liu, J.Y. Ma, Y.Z. Chen, Q.Q. Tian, Y. Shen, X.S. Wang, B. Chen and S.Z. Yao (2009). Investigation of flavonoid profile of Scutellaria bacalensis Georgi by high performance liquid chromatography with diode array detection and electrospray ion trap mass spectrometry, J. Chromatogr. A 1216, 4809-4814.

[5] C.Y. Li, Y.C. Hou, P.D.L. Chao, C.S. Shia, I.C. Hsu and S.H. Fang (2010). Potential ex vivo immunomodulatory effects of San-Huang-Xie-Xin-Tang and its component herbs on mice and humans, J. Ethnopharmacol. 127, 292-298.

[6] E.S. Smolianinov, V.E. Goldberg, M.G. Matiash, V.M. Ryzhakov, D.A. Boldyshev, V.I. Litvinenko and A.M. Dygai (1997). Effect of Scutellaria baicalensis extract on the immunologic status of patients with lung cancer receiving antineoplastic chemotherapy, Eksp. Klin. Farmakol. 60, 49-51.

[7] V.E. Goldberg, V.M. Ryzhakov, M.G. Matiash, E.A. Stepovaya, D.A. Boldyshev, V.I. Litvinenko and A.M. Dygai (1997). Dry Scutellaria baicalensis (SB) extract as a hemostimulator in antitumor chemotherapy of lung cancer, Eksp. Klin. Farmakol. 60, 28-30.

[8] Z. Blach-Olszewska, B. Jatczak, A. Rak, M. Lorenc, B. Gulanowski, A. Drobna and E. Lamer-Zarawska (2008). Production of cytokines and stimulation of resistance to viral infection in human leukocytes by Scutellaria baicalensis flavones, J. Interferon Cytokine Res. 28, 571-581.

[9] B. Orzechowska, R. Chaber, A. Wisniewska, E. Pajtasz-Piasecka, B. Jatczak, I. Siemieniec, B. Gulanowski, A. Chybicka and Z. Blach-Olszewska (2014). Baicalin from the extract of Scutellaria baicalensis affects the innate immunity and apoptosis in leukocytes of children with acute lymphocytic leukemia, Int. Immunopharmacol. 23, 558-567.

[10] M. Chu, L. Xu, M.B. Zhang, Z.Y. Chu and Y.D. Wang (2015). Role of Baicalin in Anti-Influenza Virus A as a Potent Inducer of IFN-Gamma, Biomed. Res. Int. 2015, 263630.

[11] S.Q. Gong, W. Sun, M. Wang and Y.Y. Fu (2011). Role of TLR4 and TCR or BCR against baicalininduced responses in T and B cells, Int. Immunopharmacol. 11, 2176-2180.

[12] J. Yang, X. Yang and M. Li (2012). Baicalin, a natural compound, promotes regulatory T cell differentiation, BMC. Complement. Altern. Med. 12, 64.

[13] D.N. Olennikov, A.V. Stolbikova, A.V. Rokhin and V.B. Khobrakova (2011). Carbohydrates from Lamiaceae. VIII. alpha-glucan from Scutellaria baicalensis roots, Chem. Nat. Compd. 47, 190-193.

[14] S.F. Ziegler, F. Ramsdell and M.R. Alderson (1994). The activation antigen CD69, Stem Cells 12, 456465.

[15] T. Werfel, M. Boeker and A. Kapp (1997). Rapid expression of the CD69 antigen on T cells and natural killer cells upon antigenic stimulation of peripheral blood mononuclear cell suspensions, Allergy 52, 465-469.

[16] J. Brush, E. Mendenhall, A. Guggenheim, T. Chan, E. Connelly, A. Soumyanath, R. Buresh, R. Barrett and H. Zwickey (2006). The effect of Echinacea purpurea, Astragalus membranaceus and Glycyrrhiza glabra on CD69 expression and immune cell activation in humans, Phytother. Res. 20, 687-695.

[17] L. Tumova, Z. Ducaiova, J. Cheel, I. Vokral, B. Sepulveda and D. Vokurkova (2017). Azorella compacta infusion activates human immune cells and scavenges free radicals in vitro, Pharmacogn. Mag. 13, 260264.

[18] T. Makino, A. Hishida, Y. Goda and H. Mizukami (2008). Comparison of the major flavonoid content of S. baicalensis, S. lateriflora, and their commercial products, J. Nat. Med. 62, 294-299.

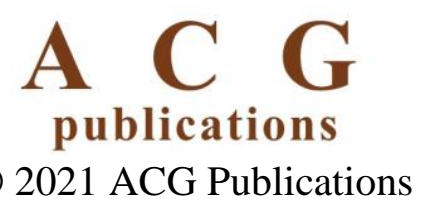

